\title{
The Effect of Psychological Capital on the Financial Performance of Local Governorates in Gaza Strip
}

\author{
Iyad Hosni Mohamed Ismail \\ Faculty of commerce - Alazhar University -Gaza-Palestine
}

\begin{abstract}
This study aimed to investigate the impact of psychological capital on the financial performance of local Governorates in Gaza Strip, in order to achieve the objectives of the study researcher relied on the literature and previous relevant studies to obtain data and information of the theoretical framework, the practical framework has been used the questionnaire to suit the subject the study and hypotheses to collect preliminary data on the subject of the study, also financial ratios analysis was made of all the municipalities of Gaza Strip over three years 2014,2015 , and 2016 to measure the financial performance, where the study was applied to all of the 25 municipalities of the Gaza Strip, (220) questionnaires were distributed using the Comprehensive count method to all the financial and administrative department staff of those municipalities, (182) questionnaires were recovered and valid for analysis, that means the recovery rate was (83\%), a statistical analysis was made for questionnaires using statistical analysis program (SPSS) and Standard Analysis Program (Eviews), and to conduct appropriate tests of this type in order to test the hypotheses and to reach indications of values that support the subject of the study. The most important findings which the study reached, the existence of a disparity in the effect of the dimensions of psychological capital (self-efficacy, hope, optimism and resilience) on the liquidity indicators and the production efficiency indicators of the local Governorates in Gaza Strip. Where there is no statistically significant effect of the dimensions of psychological capital (Self-efficacy, hope, optimism and resilience) on the indicators of financial flexibility and Productive efficiency of the individual indicators for the local Governorates in the Gaza Strip. The efficiency of financial performance during the years 2014, 2015 and 2016 was low. there is statistically significant effect of resilience dimension due to the age variable, while there is no statistically significant effect of the other dimensions of psychological capital (Self-efficacy, hope, and optimism) due to the controllable variables (age, qualification, experience, and current job), and that psychological capital development strategies (job satisfaction, Incentives and rewards, the provision of an appropriate work environment, and equity in the municipality) have a positive role in improving the financial performance of the local Governorates in Gaza Strip. The most important recommendations: is the need of the municipal administration to enhance psychological capital, job satisfaction, justice and equity, pay attention to incentives and periodic rewards, and provide an appropriate work environment for municipal employees, which will enhance the psychological capital, enhance organizational and municipal programs in the municipal strategic plan, and to find ways to increase collection efficiency and reduce indebtedness.
\end{abstract}

Keywords: Psychological Capital - Financial Performance - Local Governorates - Financial Ratios.

DOI: $10.7176 / \mathrm{JEP} / 11-24-09$

Publication date: December $31^{\text {st }} 2020$

\section{Introduction}

The contributions of the psychology field to wellbeing and happiness are recognized by a wide range of fields. It includes relationships, education, health, sports, military, work, and life in general. Although that at the beginning of the twentieth century, both scientists Seligman and Hiczanmehaile noted that since World War II, most of the psychology focus was on treatment of mental illness and dysfunctional behavior instead of understanding and facilitating the natural performance. It also focuses on the growth and development of healthy individuals.

This group of knowledge which is related to treating mental diseases under "Disease Form" is found in scientific journals that are widely accredited and applied in best practices. This helps make healthy people work normally. However, what makes them happy, productive, creative, and capable to live, work, love is still insufficient. It largely left the narrative evidence in the usual self-reliance literature. Based on this recognized gap, Martin Seligman made in his famous presidential title of the American Psychiatric Association of 1998, advocating "positive psychology" that explicitly focuses on studying and understanding the well-being of "Ordinary" people, productivity, optimal performance, achieve one's full potential (Seligman et al. 2005).

In addition, the area of psychology seems to hit a chord for scientists and practitioners of psychiatry. Researches on positive psychology and evidence-based applications have increased dramatically over nearly two decades. There have been hundreds of articles in prestigious magazines, numerous scholarly booklets, specialized journals, bestsellers, a magazine specializing in positive psychology, and also related to management and organizational behavior, several streams of research and practice have emerged, applying positive psychology to the workplace (Luthans \& Avolio, 2009).

Local government bodies in Palestine are not-for-profit organizations that seek to cover their operating 
expenses, such as building, cleaning, water, sanitation, crafts, professions, and industries, in return for providing basic services to citizens such as paving and maintaining roads, opening new roads, monitoring the shops, clinics, and markets. Due to the increasing activity of local authorities, especially in recent times, it is necessary to train the staff working on the use of performance measures in general and financial performance, in particular, to assist in strategic planning, social responsibility, communication with citizens, upgrading service quality, decisionmaking and performance improvement.

The financial performance of the local authorities is directly affected by the quality of decision-making for the financial management of the local authority. It must be evaluated using a consistent and integral set of indicators. And thus, it ensures comparability on the same conditions for the development of the different administrative and regional authorities at the same administrative level, which are located at the same administrative level, or at different levels, in the same state or in different states.

\section{Psychological Capital}

Luthans et al. (2004) points out that the term " Psychological capital" was briefly mentioned in various works in economics, investment, sociology, and when positive psychology emerged a few years ago, the psychologist Seligman demonstrated a challenge A great goal is to change the preoccupation with what is wrong with people, and the shift to what is right and good for them, more specifically focused in his views on the strengths rather than the weaknesses, and on health and vitality rather than diseases.

Psychological Capital consists of four components represented in (Hope: the ability of the individual to be clear about the goals, to develop specific plans to achieve those goals, to be able to be established, and to have the enthusiasm to sustain efforts towards those goals (Snyder, 2002), Self-efficacy: means people's confidence in their own abilities, through their own actions, which can lead to the desired outcome as it is not about what they will do but what they believe they can do. Self-efficacy is important in adopting positive behaviors to intervene and stop unhealthy behaviors, where increased self-efficacy is essential to guiding the positive habits of positive interventions (Maddux, 2000), Resilience is the ability to generate a positive outcome despite a serious threat (Masten, 2001), Optimism is an explanatory reason used by the individual in his response to events. It is intended to evaluate events that occurred in the past in exchange for future orientation only. An optimistic individual attributes the results of positive events to ongoing internal efforts, while attributing accidents or negative consequences to unstable external events cannot be avoided (Avey et al, 2010).

\section{Financial performance}

Financial performance is that the Company's revenues are summarized by an accounting record based on the measurement of policies and transactions related to the Company's financial position within a certain period of time and in comparison to other similar companies (Laurence, 2011), The Financial Performance evaluation is defined as the evaluation of an essential provision for the management of financial, physical and natural resources in an integrated manner and the extent to which they are best used to achieve the objectives of the beneficiaries, that means the process of measuring results achieved or anticipated in the light of predetermined criteria (Alghani, 2014). It is worth mentioning that financial performance evaluation with financial analysis method used in this research, which defined as a method of calculating and commenting on financial ratios to analyze and monitor an enterprise's performance (Itman \& Zutter, 2013).

\section{Local Governorates}

Local Governorates "Those rural and urban political subdivisions that fall under the national level and are constituted by law and have considerable control over local affairs, including the authorities in the provinces, municipalities, towns, villages and others." (Havenga, 2003).

\section{Study Hypotheses}

To achieve the objectives of the study and answer its questions has been editing three main hypotheses are derived from other sub-hypotheses as follows:

\section{First main hypothesis}

There is a statistically significant indication effect of psychological capital dimensions on the financial performance of local governorates in the Gaza Strip.

To test this hypothesis, the following sub-hypotheses were drafted:

There is a statistically significant indication effect of psychological capital dimensions on liquidity indicators for local governorates in Gaza Strip.

There is a statistically significant indication effect of psychological capital dimensions on financial flexibility indicators for local governorates in Gaza Strip.

There is a statistically significant indication effect of psychological capital dimensions on Productive efficiency 
indicators for local governorates in the Gaza Strip.

There is a statistically significant indication effect of psychological capital dimensions on productive efficiency indicators per capita in local governorates in the Gaza Strip.

\section{Second main hypothesis}

There is statistically significant indication effect between psychological capital dimensions of financial and administrative employees in local governorates attributed to control variables, which are represented in (Age, scientific qualification, years of experience, and present position).

\section{Third main hypothesis}

There is a positive role of psychological capital developing strategies in improving financial performance in local governorates.

\section{Figure 1: the study variables}

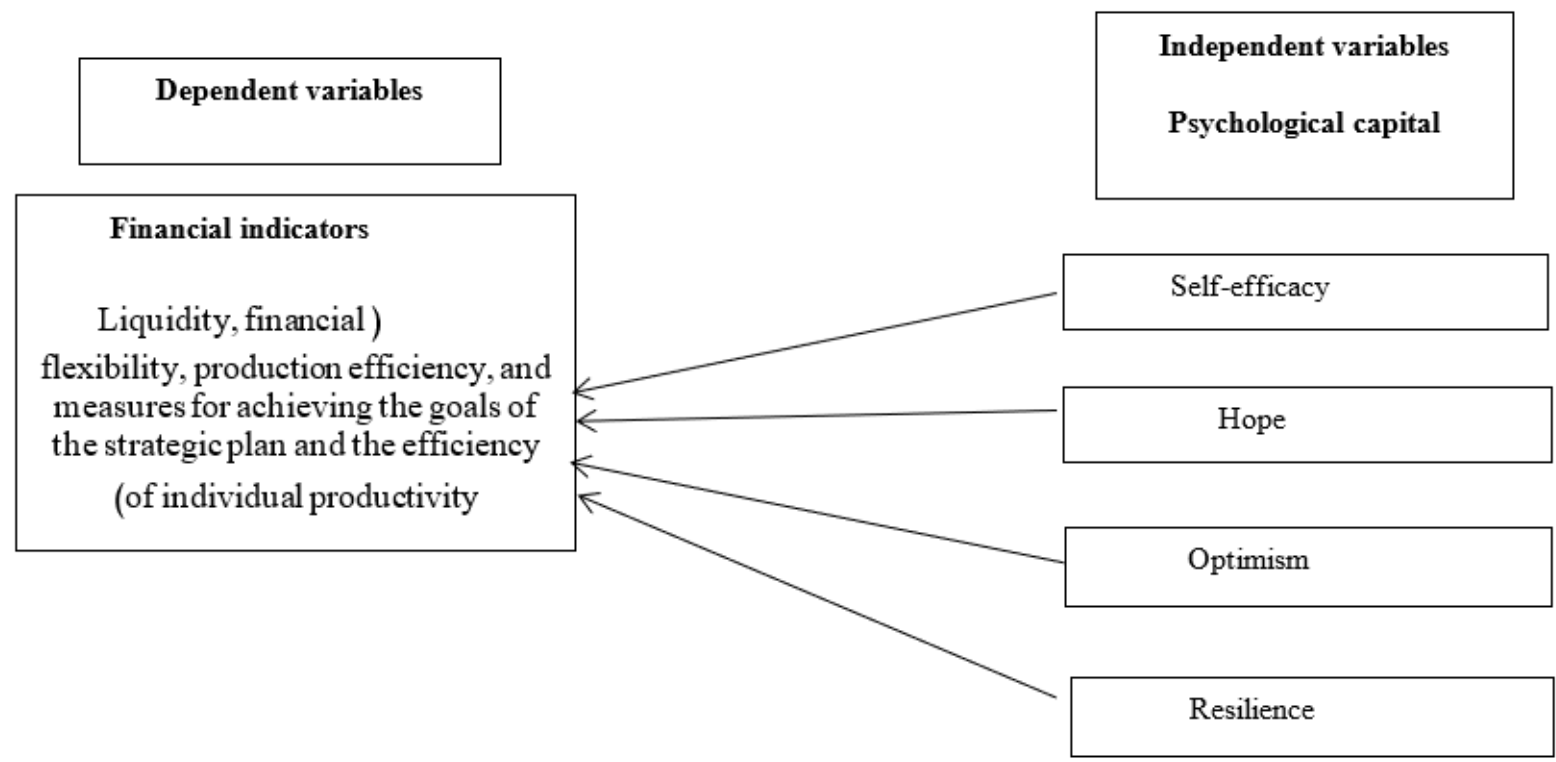

\section{Methodology}

About 220 employees of the financial and administrative department in the municipalities of Gaza Strip distributed in twenty five municipalities in five governorates (North Gaza governorate, Gaza governorate, central governorate, Khan Younis governorate and Rafah governorate), were recruited to participate in data collections for accuracy and correctness, a comprehensive survey method was used for all members of the community, the number of questionnaires retrieved was 182 questionnaires to the total population of the study of 220 questionnaires is $82.73 \%$ were used for analysis, the average respondent in our population was 40 years old, worked for his/her organization on average 10 years. $76.9 \%$ of the study population "males", $23.1 \%$ of the study population "females". Wide range of specializations were represented in the population, including accounting, finance, information systems, business administration, economics, and banking, also municipal financial ratios were used for the financial analysis of municipalities financial statements for three years 2014, 2015, and 2016.

\section{Measures}

Independent variables

The independent variable in this study was the psychological capital (PsyCap) for the employees of financial and administrative department in the municipalities. PsyCap was measured utilizing the 24-item psychological capital questionnaire (PCQ) developed and validated by Luthans and colleagues (Luthans et al., 2006); Modifications were made to suit the subject and the research environment. Participants rated their responses on a 1-5 rating scale, anchored by strongly disagree (1) and strongly agree (5). Participants evaluated themselves using this scale. A sample item for participants' evaluation of their own resources is, "If I should find myself in a jam at work, I could think of many ways to get out of it." The reliability $(\alpha)$ of this measure was .977 for the employees' rating of their own PsyCap.

Dependent variables

Four dependent variables were explored in this study: liquidity indicators, financial flexibility/other sources of revenues, Productive efficiency indicators, and productive efficiency indicators per capita.

The cross-sectional analysis, which is often considering the first year as the base year. Since the economic 
and political conditions in Gaza Strip in recent years is unstable and there is a marked discrepancy in the financial reports, each municipality has been analyzed separately in the years 2014-2015, 2016, And then a three-year arithmetic mean was applied for each unit separately for each municipality. The average of the same percentage was then calculated for all municipalities' averages during the three years. This average was considered a criterion for each percentage of the financial ratios and a basis for comparison with the financial ratios of the municipalities. and then A total average of all averages for all municipalities combined for the three years has been worked out. "Each ratio of the average financial ratios represents all municipalities during the three years 2014-2015, 2016 in one proportion.

\section{Analysis}

Table 1: The results of the estimation of the multiple regression model of average creditworthiness

\begin{tabular}{|c|c|c|c|c|}
\hline Independent variables & Coefficients & S.E. & "t" & "P-Value" \\
\hline Self-efficacy & $25.088^{*}$ & 11.776 & 2.13 & 0.046 \\
\hline Hope & -20.351 & 10.047 & -2.026 & 0.056 \\
\hline Optimism & $-23.005^{*}$ & 10.63 & -2.164 & 0.043 \\
\hline Resilience & $24.585^{*}$ & 10.272 & 2.393 & 0.027 \\
\hline Constant & -30.394 & 38.693 & -0.786 & 0.441 \\
\hline
\end{tabular}

The value of the adjusted mean is 0.343 . This means that the independent variables (Psychological capital components) included in the model account for $34.3 \%$ of the change in the dependent variable (average creditworthiness) and the remaining $65.7 \%$ due to factors and variables other than In addition to random sampling errors. In general, the significant linear regression model $(F)$ is observed by means of the (F) test, where the test significance level $(0.013)$ is less than 0.05 .

Table 2: Estimation of the multiple regression model of average debt indicators

\begin{tabular}{|c|c|c|c|c|}
\hline Independent variables & Coefficients & S. E. & "t" & "P-Value" \\
\hline Self-efficacy & -0.632 & 5.533 & -0.114 & 0.91 \\
\hline Hope & -3.305 & 4.72 & -0.7 & 0.492 \\
\hline Optimism & -1.08 & 4.995 & -0.216 & 0.831 \\
\hline Resilience & 6.874 & 4.826 & 1.424 & 0.17 \\
\hline Constant & -9.458 & 18.18 & -0.52 & 0.609 \\
\hline
\end{tabular}

It is clear that the model is insignificant and the variables are insignificant. Consequently, the independent variables (self-efficacy, hope, optimism and resilience) do not affect the average indebtedness, which means the ability of the local authority to liquidate its debts with surplus operating expenses not psychological capital.

Table 3: Estimation of the Multiple Regression Model of Average Indicators of Financial Independence

\begin{tabular}{|c|c|c|c|c|}
\hline Independent variables & Coefficients & S. E. & "t" & "P-Value" \\
\hline Self-efficacy & -7.562 & 12.48 & -0.606 & 0.551 \\
\hline Hope & -23.812 & 10.647 & -2.236 & 0.037 \\
\hline Optimism & 3.019 & 11.266 & 0.268 & 0.792 \\
\hline Resilience & 9.737 & 10.886 & 0.894 & 0.382 \\
\hline Constant & 161.713 & 41.006 & 3.944 & 0.001 \\
\hline
\end{tabular}

The variables in the model are insignificant and the variables are insignificant. Therefore, the independent variables (self-efficacy, hope, optimism and resilience) do not affect the average of financial independence due to the complex political and economic conditions that limit the existence of grants.

Table 4: Estimation of the Multiple Regression Model of the Average Capital Investment Effort Indicators

\begin{tabular}{|c|c|c|c|c|}
\hline Independent variables & Coefficients & S. E. & "t" & "P-Value" \\
\hline Self-efficacy & 6.886 & 12.025 & 0.573 & 0.573 \\
\hline Hope & 14.531 & 10.259 & 1.416 & 0.172 \\
\hline Optimism & -26.476 & 10.855 & -2.439 & 0.024 \\
\hline Resilience & -7.143 & 10.489 & -0.681 & 0.504 \\
\hline Constant & 55.961 & 39.51 & 1.416 & 0.172 \\
\hline
\end{tabular}

The independent variables (self-efficacy, hope, optimism and resilience) do not affect the average capital investment effort, which means the growth of the capital investment expenditure of the local authority because there is an approved annual budget and a clear financial system that determines this expenditure and is not related to the dimensions Psychological capital. 
Table 5: Estimation of the multiple regression model for the average efficiency indicators of collection of total revenue

\begin{tabular}{|c|c|c|c|c|}
\hline Independent variables & Coefficients & S. E. & "t" & "P-Value" \\
\hline Self-efficacy & -1.858 & 17.756 & -0.105 & 0.918 \\
\hline Hope & 26.197 & 15.148 & 1.729 & 0.099 \\
\hline Optimism & -11.167 & 16.028 & -0.697 & 0.494 \\
\hline Resilience & -17.84 & 15.487 & -1.152 & 0.263 \\
\hline Constant & 87.964 & 58.338 & 1.508 & 0.147 \\
\hline \multicolumn{2}{|l}{$\mathbf{( F )}=\mathbf{0 . 3 7}(\mathbf{F})=\mathbf{1 . 1 0}$ 'determination coefficient $\mathbf{0 . 0 1 7 *}$} \\
\hline
\end{tabular}

The independent variables (self-efficacy, hope, optimism and resilience) do not affect the average collection efficiency of total revenues due to the complex political and economic circumstances that limit the reliability of the budget.

Table 6: The results of the estimation of the multiple regression model for the average productivity indicators for municipal employees

\begin{tabular}{|c|c|c|c|c|}
\hline Independent variables & Coefficients & S. E. & "t" & "P-Value" \\
\hline Self-efficacy & -0.154 & 0.133 & -1.161 & 0.259 \\
\hline Hope & $-0.320^{* *}$ & 0.113 & -2.833 & 0.01 \\
\hline Optimism & $0.466^{* *}$ & 0.12 & 3.899 & 0.001 \\
\hline Resilience & 0.084 & 0.116 & 0.73 & 0.474 \\
\hline Constant & 0.114 & 0.436 & 0.261 & 0.797 \\
\hline \multicolumn{2}{|r}{$\mathbf{( F )}=\mathbf{0 . 0 0 3}(\mathbf{F})=\mathbf{5 . 6 5}$ 'determination coefficient 0.436* } \\
\hline
\end{tabular}

It is clear that the value of the adjusted determination factor is $(0.436)$. This means that the independent variables (psychological capital components) included in the model explain $43.6 \%$ of the change in the dependent variable (average productivity of municipal employees). The remaining 56.4\% And other variables not included in the model in addition to the errors of random estimation, and generally note through the test (F) significant multi-linear regression model where the level of test indication $(0.003)$ less than 0.05 .

Table 7: The results of the estimation of multiple regression model for the average productivity of the salaries

\begin{tabular}{|c|c|c|c|c|}
\hline Independent variables & Coefficients & S. E. & "t" & "P-Value" \\
\hline Self-efficacy & -2.665 & 10.358 & -0.257 & 0.8 \\
\hline Hope & -15.037 & 8.837 & -1.702 & 0.104 \\
\hline Optimism & 0.934 & 9.35 & 0.1 & 0.921 \\
\hline Resilience & 7.305 & 9.035 & 0.809 & 0.428 \\
\hline Constant & 127.642 & 34.033 & 3.751 & 0.001 \\
\hline \multicolumn{2}{|r}{$\mathbf{( F )}=\mathbf{0 . 5 4 5}(\mathbf{F})=\mathbf{0 . 7 8}$ 'determination coefficient $\mathbf{0 . 1 3 6 *}$} \\
\hline
\end{tabular}

The independent variables (self-efficacy, hope, optimism and resilience) do not affect the average productivity efficiency of the payroll. This is due to the limited scope of financing salaries and wages of the Authority's revenues, which is approved in the annual budget of the Authority.

Table 8: Results of the estimation of the multiple regression model for the average efficiency ratio indicators

\begin{tabular}{|c|c|c|c|c|}
\hline Independent variables & Coefficients & S. E. & "t" & "P-Value" \\
\hline Self-efficacy & -7.906 & 15.47 & -0.511 & 0.615 \\
\hline Hope & 1.335 & 13.198 & 0.101 & 0.92 \\
\hline Optimism & -17.182 & 13.965 & -1.23 & 0.233 \\
\hline Resilience & 11.13 & 13.494 & 0.825 & 0.419 \\
\hline Constant & 141.297 & 50.829 & 2.78 & 0.012 \\
\hline
\end{tabular}

$(F)=0.629$ ، $(F)=0.65$ 'determination coefficient $0.115 *$

The independent variables (self-efficacy, hope, optimism and resilience) do not affect the average efficiency ratio, which means the ratio of expenditure to income because it is approved in the annual budget.

Table 9: The results of the estimation of the multiple regression model of the average level of service level indicators at the municipal level

\begin{tabular}{|c|c|c|c|c|}
\hline Independent variables & Coefficients & S. E. & "t" & "P-Value" \\
\hline Self-efficacy & 10.047 & 9.808 & 1.024 & 0.318 \\
\hline Hope & -4.341 & 8.367 & -0.519 & 0.61 \\
\hline Optimism & -18.041 & 8.853 & -2.038 & 0.055 \\
\hline Resilience & 3.678 & 8.555 & 0.43 & 0.672 \\
\hline Constant & 41.465 & 32.225 & 1.287 & 0.213 \\
\hline \multicolumn{2}{|l}{$\mathbf{0 . 3 5 0}$ ‘(F) $=\mathbf{1 . 1 7}$ 'determination coefficient 0.028* } \\
\hline
\end{tabular}


The independent variables (self-efficacy, hope, optimism and resilience) do not affect the average level of service, which indicates the ratio of maintenance expenses to fixed assets of total operating expenses as it is an estimated and approved amount in the annual budget.

Table 10: The results of the estimation of the multiple regression model for the average per capita share of total revenues of local authorities.

\begin{tabular}{|c|c|c|c|c|}
\hline Independent variables & Coefficients & S. E. & "t" & "P-Value" \\
\hline Self-efficacy & -298.418 & 319.425 & -0.934 & 0.361 \\
\hline Hope & -48.436 & 272.509 & -0.178 & 0.861 \\
\hline Optimism & -0.446 & 288.339 & -0.002 & 0.999 \\
\hline Resilience & 151.601 & 278.611 & 0.544 & 0.592 \\
\hline Constant & 1425.755 & 1049.509 & 1.358 & 0.189 \\
\hline
\end{tabular}

The independent variables (self-efficacy, hope, optimism and resilience) do not affect the average per capita share of total income. This is a comparison index with local authorities of the same size inside or outside the country.

In general, the linear regression model shows that there is a disparity between the components of psychological capital in influencing the level of financial performance. It was ranked first in terms of the effect on the dependent variable (average productivity of municipal employees) by a coefficient of (0.436), And this effect was statistically significant at level (0.01), which indicates that the psychological capital has a clear impact on the productive efficiency of the employees of the financial and administrative department in the municipalities, and second place in terms of impact on the variable (average creditworthiness) A limit of (0.343) and This effect is statistically significant at level (0.01), which in turn reflects the effect of psychological capital on the municipality's ability to meet its short-term obligations. The rest of the financial indicators did not have an impact on the psychological capital, Self-efficacy, which is to have the confidence to make the necessary efforts to succeed in challenging tasks, and hope to persevere and pursue goals, and reorient the paths towards those goals when necessary to achieve success and optimism that creates the positive characteristic of achieving success today and touch And the flexibility that reflects the return to the normal situation in the event of the individual's problems and tribulations in the pursuit of the objectives of the staff of the Department of Finance and Administrative impact on financial performance, and based on the results of the hypothesis reached it was found to have a significant effect of the significance of the dimensions of psychological capital On financial performance in local authorities. Table 11: mean and the probability value (Sig.) for each of the most important areas to develop psychological capital.

\begin{tabular}{|l|c|c|c|c|c|c|}
\hline \multicolumn{1}{|c|}{ Statement } & mean & $\begin{array}{c}\text { Percentage } \\
\text { mean }\end{array}$ & Variance & "t" & $\begin{array}{c}\text { Probability } \\
\text { value (Sig.) }\end{array}$ & Ranking \\
\hline $\begin{array}{l}\text { Employee satisfaction improves } \\
\text { the psychological capital. }\end{array}$ & 4.45 & 89.01 & 0.404 & 30.802 & 0 & 2 \\
\hline $\begin{array}{l}\text { Employees' periodic incentives } \\
\text { and bonuses improve } \\
\text { psychological capital. }\end{array}$ & 4.46 & 89.23 & 0.371 & 32.352 & 0 & 1 \\
\hline $\begin{array}{l}\text { Providing an appropriate working } \\
\text { environment for the employee } \\
\text { improves psychological capital. }\end{array}$ & 4.33 & 86.59 & 0.432 & 27.287 & 0 & 3 \\
\hline $\begin{array}{l}\text { Justice and equity among staff lead } \\
\text { to improved psychological capital. }\end{array}$ & 4.42 & 88.46 & 0.544 & 26.035 & 0 & 4 \\
\hline $\begin{array}{l}\text { Policies that promote } \\
\text { psychological capital and well- } \\
\text { being can improve labor } \\
\text { productivity and help reduce } \\
\text { unemployment. }\end{array}$ & 4.3 & 86.04 & 0.566 & 23.359 & 0 & 5 \\
\hline $\begin{array}{l}\text { The municipal strategic plan } \\
\text { includes a side to enhance } \\
\text { psychological capital. }\end{array}$ & 3.74 & 74.73 & 1.311 & 8.674 & 0 & 5 \\
\hline \begin{tabular}{l} 
All paragraphs of the field together \\
\hline
\end{tabular}
\end{tabular}

In general, mean is 4.28 , the Percentage mean is $85.68 \%$, the test value is 33.732 , the variance is 0.264 , and the probability value (.Sig) is 0.000 . Therefore, the area of "most important strategies for psychological capital development" Indicating that the average response rate for this field is significantly different from the average approval level of 3, which means that there is a high degree of approval by the members of the community on the paragraphs of this area, which means the validity of the hypothesis that there is a positive role for capital 
development strategies Psychological improvement in the financial performance of local governorates in Gaza Strip.

(Cole, 2006) found the same result. The results suggest that policies that promote psychological capital and well-being can improve labor productivity and help reduce unemployment.

It is also consistent with the study (Abdelwahab, 2012), which showed that the interaction between psychological capital and mental property has a significant impact on both job satisfaction and organizational commitment.

The results of the study (Tain, 2015) also showed the same results. The participants in the study showed that there is a desire by the college administrations to reward creative individuals and overcome the obstacles to exchange ideas, ideas and information that enable them to develop themselves. Quality creations.

\section{Discussion \& Limitations}

Discussion

The importance of this study is being the first of its kind to address the extent of psychological capital impact as stand-alone itself, and different from the human capital on the financial performance of the local governorates in Gaza Strip.

Analysis of the questionnaires revealed that the employees of the financial and administrative department in the local governorates in Gaza Strip have the psychological capital dimensions of self-efficacy of $80 \%$, hope of $79 \%$, optimism of $71 \%$, and resilience of $78 \%$. The effect of the dimensions of psychological capital (self-efficacy, hope, optimism, and resilience) on the average liquidity indicators in local governorates as this;

* There was a statistically significant positive effect on self-efficacy and resilience on the average creditworthiness indicators of local governorates in Gaza Strip.

* There was a statistically significant negative effect on the average of the indicators of creditworthiness of the local governorates in Gaza Strip.

*There was no statistically significant effect of the indicator on the average credit indicators of local governorates in Gaza Strip.

*There was also no statistically significant effect of the psychological capital dimensions (self-efficacy, hope, optimism, and resilience) on the average debt indicators of the local governorates in Gaza Strip.

The results of the study showed that there is no statistically significant effect of the dimensions of psychological capital (self-efficacy, hope, optimism, and resilience) on the average indicators of financial flexibility represented by indicators of financial independence and indicators of capital investment effort and efficiency indicators of total revenues in the local governorates in Gaza Strip.

There was also a difference in the effect of the dimensions of psychological capital (self-efficacy, hope, optimism, and resilience) on the average indicators of productive efficiency of the local governorates in Gaza Strip as this:

*There is no statistically significant effect of self-efficacy and resilience on average productivity indicators for employees in local governorates.

*There is a statistically positive effect of the optimism variable on the average productivity efficiency indicators for employees in local governorates.

*There is a statistically significant negative effect on the indicator of hope on the average indicators of productivity of employees in local governorates.

*There was also no statistically significant effect of the psychological capital dimensions (self-efficacy, hope, optimism, and resilience) on the average indicators of productive efficiency of salaries.

*The results of the study showed that there is no statistically significant effect of the psychological capital dimensions (self-efficacy, hope, optimism, and resilience) on the average indicators of productivity per capita of efficiency indicators and indicators of average level of service at the municipality level and indicators of the average per capita share of total revenues.

The study revealed that the efficiency of financial performance during the years 2014, 2015, and 2016 were low. There is positive role for psychological capital development strategies (job satisfaction, incentives, rewards, provision of an appropriate working environment and equity in the municipality) in improving the financial performance of the local governorates.

Limitations

The limits and scope of the study include:

-The limits of the place: the twenty-five local governorates in Gaza Strip.

-Human Boundaries: two hundred and twenty employees, representing employees working in financial and administrative affairs in the local governorates in Gaza Strip.

-Time Limits: Annual financial reports of local governorates in Gaza Strip for the three years 2014, 2015 and 2016. 


\section{Conclusion}

In light of the findings of the study, the following recommendations were proposed:

*Work to strengthen the psychological capital of employees in the strategic plan for municipalities because it is an important factor in raising the efficiency of financial performance and increase labor productivity and reduce the unemployment rate.

*The need for municipal administration to promote job satisfaction among municipal employees, thus enhancing psychological capital, which will positively affect financial performance.

*Paying attention to the incentives and periodic bonuses for municipal employees, which will enhance psychological capital, which will positively affect financial performance.

*Providing an appropriate working environment for employees by providing the necessary work requirements for the employee to perform his work to the fullest, thus enhancing the psychological capital which will positively affect the financial performance.

*Enhancing the presence of justice and fairness among municipal employees by applying regulations and laws to all municipal employees, which will enhance psychological capital and will positively affect financial performance.

*Work to enhance the administrative, financial, organizational and programmatic performance of the municipality in the strategic plan for municipalities.

*Building the capacity and training of the financial and administrative staff in the municipalities of Gaza Strip in order to increase its efficiency in general, and awareness of the direction of rationalization of spending and not wasting in activities that are not useful to the municipality in particular.

*Improve the status of services provided to citizens by improving and developing various development areas in order to improve the level of services provided in the strategic plan for municipalities.

*The need for housing, industrial and agricultural income-generating projects in the municipal strategic plan.

*Finding ways to increase the efficiency of collection and reduce indebtedness, which in turn will result in an operational surplus which will be the backbone to improve financial performance.

\section{References}

Abdul Qader, Mohammed, (2016), the effect of psychological capital behavior of organizational citizenship, application to employees of industrial companies affiliated to the public business sector Dekahalia Governorate, Central Library, Mansoura University - Faculty of Commerce - Department of Business Administration.

Abdulghani D. (2014) "The Effect of Financial Structure on the Financial Performance for the Economic Organization from 2012 to 2014", Qazdi Merbah University, Algeria.

Al-Hassani, Kamal, (2013), Psychological Capital and its Impact on Employment absorption, Muthanna Journal of Administrative and Economic Sciences Volume (3), Issue (6).

Alkerdawi, Mustafa, (2013), the impact of career alignment in the relationship between psychological capital and the level of organizational stress feeling among workers in the governmental sector in the province of Dekahalia, Journal of Public Administration, General Management Institute of Riyadh, Volume (53), number (3).

Cole, K. (2006). "Wellbeing, Psychological Capital, and Unemployment: An Integrated Theory" Paper presented at the joint annual conference of the International Association for Research in Economic Psychology (IAREP) and the Society for the Advancement of Behavioral Economics (SABE), 5-8 July 2006 Paris, France.

Dulaimi, Mariam, (2016), Characteristics of Women's Leadership and its Impact in The development of psychological capital: test the roll rate of force experience study Analytical from The point of view of subordinates in a Special Education Schools in Amman, Master Thesis, Middle East University - Business School - Business Administration Department.

Havenga, B. (2003). The restructuring of local government with specific reference to the City of Tshwane. Pretoria: University of Pretoria.

Kanza, Boderham, (2018), the effect of work Pressure On Positive Psychological capital, Case Study on Public Enterprise Hospital Saad Dahlab University, MA thesis discussed and approved, Qasdy Merbah University, Faculty of Economic, development, \& Commercial science Steering, Commercial science Section.

Khuayn, Sondos, (2017), the effect of psychological capital and social capital on the creative organizational exploratory study of the views of a sample of managers in the Iraqi Commission for Computers and Informatics, Journal of Baghdad College of Economic Sciences University, the University of Mustansiriya College Administration and the economy, number (50).

Laurence, M. (2011). Measuring Financial Performance: A Critical Key to Managing Risk, National Crop Insurance Services, Inc.

Luthans F, Avolio BJ. (2009): The "point" of positive organizational behavior. J. Organ. Behav. Iss. 30 PP. 291 307. 
Luthans, F., Lythans, K. W. and Luthans, b. T. (2004), " Positive psychological capital: Beyond human and social capital, Business Horizons, 47/1, January-February, PP.45-50 .

Luthans, F., Avolio, B., Avey, J., \& Norman, S. (2006). Psychological capital: Measurement and relationship with performance and satisfaction (Working Paper No. 2006-1).

Maclean, S. (2012) "assessing the financial viability of selected urban and rural municipalities in the eastern cape". Submitted in Fulfillment for The Degree of Doctor of Administration in The Faculty of Management and Commerce Department of the Public Administration University of Fort Hare.

Maddux, J. E. (2000). Self-efficacy: the power of believing you can. In C. R. Snyder, \& S. J. Lopez (Eds.), Handbook of positive psychology, PP. 1-23.

Mahdi, Safa, (2018), the Reflection of positive Psychological capital on the development of creative behavior to workers, a research field in a sample of Ministry of Construction and Housing companies, Journal of Dinars, Baghdad University - Administration \& economics College, number (12).

Masten, A. S. (2001). Ordinary Magic: Resilience process in development. American Psychologist, Iss. 56, PP. 227-238.

Sahar, al - Azzawi, (2014), positive psychological capital and compatibility of vocational and their impact in a Strategic Performance of Human Resources a field study of sample views from Teaching the faculties of the University of Mustansiriya, Ph.D. thesis, Mustansiriya University - College of Management and Economics - Department of Business Administration.

Saleh, Rashad, (2016), The Effect of Psychological Capital to achieve organizational Commitment, field study in public Company for the fertilizer industry in Basra, Journal of Economic Sciences - Basrah University Faculty of Management and Economics - Department of Business Administration, Issue (41), vol. (11).

Seligman MEP, Steen TA, Park N, Peterson C. (2005): Positive psychology progress: empirical validation of interventions. Am. Psychol. 60, PP. 410-21.

Snyder, C. R. (2002). Hope theory: Rainbows in the mind. Psychological Inquiry, Iss. 13, PP. 249-275.

Tain, Youssef, (2015), the Effect of Positive Psychological Capital on Creative Performance, Qadisiyah Journal of Administrative and Economic Sciences, Vol. (17), Issue (3).

Taştan, S. (2016) " Psychological Capital: A Positive Psychological Resource and Its Relationship with Creative Performance Behavior" Anadolu University Journal of Social Sciences, Vol.: 16 - Sayı / No: 2 PP. 101-118. 